\title{
SISTEM INOVASI : PERAN DAN TANTANGAN DALAM MENDUKUNG PEMBANGUNAN PERTANIAN
}

\author{
Julian Witjaksono ${ }^{1^{\star}}$ \\ ${ }^{1}$ Balai Pengkajian Teknologi Pertanian (BPTP) Sulawesi Tenggara \\ ${ }^{*}$ Corresponding author: julianahafid0771@gmail.com
}

To cite this article:

Witjaksono, J. (2020). Sistem Inovasi : Peran dan Tantangan dalam Mendukung Pembangunan Pertanian. Jurnal IImiah Membangun Desa dan Pertanian, 5(4), 117 - 121. doi:http://dx.doi.org/10.37149/jimdp.v5i4.13107

Received: July 25, 2020; Accepted: August 26, 2020; Published: August 31, 2020

\begin{abstract}
Innovation system as the added value for economic growth needs more attention not only on the national scale but also on the regional scale, particularly in agriculture. This study is the assessment of the innovation system particularly about the achievement of the agricultural innovation system in regional development. The research method was employed in 2015 by purposive sampling with the number of respondents was about 30 . The respondents came from the stakeholders of farmers, university, private sector, and regional research institution. The sample area has been chosen in Konawe District, North Konawe District and East Kolaka as represent of this research. This paper aims to describe the data and information related to the evaluation worked on regional research and development institutions in supporting the innovation system. This assessment has shown that the development of the agricultural innovation system in regional autonomy faced some constraints and weaknesses, viz. Less synchronization, less coordination, lack of research funding, and less infrastructure.
\end{abstract}

Keywords : agriculture; economic; institution; regional

\section{PENDAHULUAN}

IImu pengetahuan dan teknologi merupakan komponen utama dalam mendukung pengembangan ekonomi. Hal ini dapat dilihat dengan adanya pergeseran ekonomi dari berbasis industri ke ekonomi berbasis pengetahuan. Ekonomi yang berbasis pengetahuan akan melahirkan inovasi untuk kesejahtreraan masyarakat dan peningkatan daya saing daerah. Oleh sebab itu, konsep Sistem Inovasi Daerah (Sida) yang telah banyak diterapkan sebagai rancangan strategi pengembangan wilayah. (Narutomo, 2014); (Lakitan, 2011); (Dadit, Agung, \& Rolenta, 2012). Oleh sebab itu, diperlukan sikap yang bijak untuk menempatkan riset sebagai bagian yang tidak terpisahkan dari sistem inovasi baik di tingkat nasional (SINas) atau di tingkat daerah (SIDa) (Lakitan, 2011); (Budi, Dian \& Saut, , 2013); (Indraprahasta, Ramdhan, \& Alamsyah, 2014).

Perwujudan sistem inovasi akan terbentuk dengan adanya aliran informasi, komunikasi dan interaksi antara lembaga penelitian dan pengguna teknologi tentang kondisi aktual yang dihadapai oleh end user dalam proses produksi dari barang dan/atau jasa sesuai permintaan konsumen (Budi et al. 2013). Sinergitas ke dua aliran tersebut mutlak diperlukan untuk menunjukan eksistensi dari sebuah sistem inovasi. Hal ini disebabkan karena, aturan yang dibuat oleh pemerintah, advokasi, dan mediasi dari peran aktor kelembagaan penelitian dan pengguna teknologi belum menjamin bahwa sistem inovasi yang dikembangkan akan berjalan dengan baik. (Boschma, 2015).

Eksistensi seperti yang telah disebutkan menjadi sesuatu yang sangat krusial dalam pengembangan teknologi melalui sentuhan inovasi yang berpengaruh pada perkembangan dan kelangsungan dari sistem inovasi untuk peningkatan nilai tambah dan daya saing produk. (Dewi, 2012). Lebih lanjut (Susana Borrás, 2013) menyampaikan bahwa teknologi tepat guna sangat dibutuhkan untuk eksistensi sistem inovasi yang lebih menekankan pada kelembagaan di sektor pertanian yang tidak lagi bersifat koersif dan instruktif yang telah lama berlangsung namun bergeser pada sifat aspiratif bilateral atau pendekatan kelembagaan sebagai state of the art antara pengambil kebijakan dan pelaksana di bidang pertanian yang lebih diarahkan pada pendekatan multi-lateral. Hal 
ini sangat diperlukan mengingat bahwa sistem inovasi daerah (SIDa) tidak melihat petani sebagai pengguna akhir namun berkedudukan sejajar dalam interaksi dua arah untuk mewujudkan eksistensi sistem inovasi (Wiwandari, Hamda, \& Satria, 2012); (Sverre, Herstad, \& Bernd, 2015). Penelitian ini bertujuan untuk mengetahui kinerja kelembagaan sistem inovasi pada beberapa lembaga kelitbangan di daerah di Sulawesi Tenggara. Melalui kajian ini diharapkan adanya perbaikan kinerja kelembagaan kelitbangan khususnya pengembangan sistem inovasi di bidang pertanian.

\section{MATERI DAN METODE}

Kajian ini merupakan kombinasi antara studi kelembagaan dan analisis kebijakan yang lebih difokuskan pada aturan pendukung, sarana dan prasarana pendukung, kemampuan kelembagaan kelitbangan dan ekosistem riset. Kajian ini telah dilaksanakan di wilayah Provinsi Sulawesi Tenggara yang meliputi wilayah Kabupaten Konawe, Kolaka Timur dan Konawe Utara. Metode pendekatan yang digunakan adalah perencanaan partisipatif perpaduan antara kualitatif dan kuantitatif. Metode ini digunakan untuk mengumpulkan data dan informasi dari seluruh pihak-pihak yang terkait dan relevan dengan penelitian ini.

Pengumpulan data primer dilakukan melalui kuisioner untuk indikator kinerja pada kapasitas kelitbangan, analisis pemangku kepentingan dan analisis kebijakan infrastruktur dengan responden yang berasal dari universitas/perguruan tinggi (5 orang), petani (5 orang) di tingkat pedesaan, lembaga kelitbangan daerah di Kabupaten Konawe, Kolaka Timur dan Konawe Utara (masingmasing 5 orang) dan swasta (5 orang). Secara keseluruhan total jumlah responden sebanyak 30 orang yang dipilih dengan metode purposive sampling. Untuk menggali data dan informasi digunakan teknik wawancara semi terstruktur berdasarkan panduan sistematis yang dapat dikembangkan sesuai kebutuhan.

Analisis pemangku kepentingan dan infrastruktur merupakan analisis data sebagai instrument kebijakan sistem inovasi yang dianggap siap apabila telah teridentifikasi hubungan sinergis antar pemangku kepentingan serta dukungan infrastruktur dalam mewadahi peran dan interaksi tersebut. Analisis pemangku kepentingan berdasarkan indikator kinerja kelembagan yang meliputi perguruan tinggi, lembaga kelitbangan (Bappeda, Balitbangda dan BPTP), swasta (sektor yang mendukung usaha di bidang pertanian/agribisnis), pemerintah (Pemerintah Daerah) dan masyarakat (petani, penyuluh, dan organisasi/asosiasi petani) dengan menggunakan nilai skala 0 - 4 secara bertingkat mulai dari 0 sebagai nilai terendah dan nilai 4 sebagai nilai yang tertinggi yang menggambarkan tingkat kesiapan kelembagaan dalam sistem inovasi. Selanjutnya, analisis infrastruktur menggambarkan tingkat kesiapan kelembagaan dalam penyediaan sarana dan prasarana kelitbangan dalam mendukung sistem inivasi di daerah yang meliputi peraturan daerah, dukungan dana, penyediaan latihan dan teknologi informasi dan komunikasi dengan skor penilaian 0-2 yang menunjukan semakin tinggi nilai skor semakin tinggi tingkat kesiapan lembaga litbang tersebut dalam kesiapan infrastruktur mendukung sistem inovasi.

\section{HASIL DAN PEMBAHASAN}

\section{Gambaran Umum Kelitbangan Daerah}

Pembangunan pertanian di daerah dalam mendukung sistem inovasi daerah selayaknya berbasis pada (dan mengoptimalkan) potensi sumberdaya yang dimiliki daerah itu sendiri (Sri, 2011). Gambaran umum kelitbangan daerah lebih difokuskan pada tiga hal utama berdasarkan hasil observasi kapasitas kelembagaan litbang di daerah, yakni : (1) kemampuan penyerapan iptek dari luar lembaga; (2) Kemampuan untuk pengembangan iptek dan pelaksanaan riset; (3) Kemampuan untuk menyebarluaskan pengetahuan dan teknologi.

Berdasarkan hasil observasi menunjukan bahwa kapasitas out-sourcing pada lembaga kelitbangan di 3 kabupaten sampel, Kabupaten Konawe memiliki kemampuan out-sourcing yang baik dibandingkan dengan 2 kabupaten lainnya (Konawe Utara dan Kolaka Timur). Hal ini disebabkan Kabupaten Konawe sudah memiliki lembaga kelitbangan sendiri yang terpisah dari Bappeda, sedangkan Konawe Utara dan Kolaka Timur belum memiliki lembaga kelitbangan sendiri karena unsur kelitbangan masih terdapat di Bappeda. Kondisi ini menyebabkan kelitbangan di 2 kabupaten tersebut (Konawe Utara dan Kolaka Timur) belum memiliki kemampuan out-sourcing yang baik karena masih tumpang tindihnya antara perencanaan dan kelitbangan di daerah.

Ditinjau dari sisi kapasitas untuk melakukan riset, kondisi tersebut juga yang mengakibatkan kemampuan kapasitas dalam hal penelitian dan pengembangan (litbang) di Kabupaten Konawe Utara dan Kolaka Timur masih rendah dibandingkan di Kabupaten Konawe. Sedangkan kemampuan diseminasi di tiga kabupaten sampel masih merata, walaupun di Kabupaten Konawe sudah memiliki 
lembaga kelitbangan namun dari sisi publikasi, teknologi informasi dan royalti belum mampu menunjukan kapasitasnya sebagai lembaga kelitbangan yang mandiri di daerah.

Hasil observasi lainnya menunjukan bahwa aliran teknologi dalam bentuk paket teknologi yang dirancang atau di design oleh para pengembang teknologi dalam hal ini lembaga litbang, universitas dan pihak swasta yang terlibat dalam penelitian dan pengembangan merupakan unsur penting utama dalam menghasilkan teknologi. Unsur esensial tersebut membutuhan dukungan yang kuat dari pemerintah daerah berupa regulasi kebijakan, fasilitas dari pemerintah daerah dan dukungan intermediasi agar teknologi tersebut sampai pada tangan pengguna dalam upaya meningkatkan kapasitas adopsi. Dengan demikian, keterkaitan fungsional antara kegiatan penelitian dan pengembangan dengan inovasi merupakan justifikasi kuat untuk menempatkan lembaga atau komunitas di bidang penelitian dan pengembangan sebagai salah satu aktor utama yang merupakan unsur pengembang teknologi khususnnya dalam pengembangan Sistem Inovasi Daerah (SIDa). Sinergitas dua arah seperti yang telah dijelaskan sebelumnya harus dilaksanakan secara intensif dan berkelanjutan sehingga menghasilkan kontribusi yang nyata bagi pengembangan sistem inovasi daerah (Susana, 2013). Sehingga, sistem inovasi daerah sebagai sebuah sistem bukan hanya merupakan sekumpulan lembaga, tetapi yang lebih penting adalah terjadinya aliran informasi dan produk antar-lembaga (Lakitan, 2013). Hasil kajian juga menunjukan bahwa selama ini Sistem Inovasi Daerah hanyalah sekumpulan lembaga yang secara fungsional belum terjadi aliran informasi IPTEK dan masih banyak yang belum menghasilkan produk-produk riset atau paket-paket teknologi, hal ini sejalan dengan hasil penelitian (Oki \& Abu, 2014).

\section{Analisis Pemangku kepentingan}

Analisis pemangku kepentingan melibatkan identifikasi peran aktor utama yang terlibat dalam kelembagaan Sistem Inovasi Daerah. Dalam analisis ini terdapat lima aktor utama yang memiliki peran penting atau sebagai pilar pengembangan inovasi, yaitu perguruan tinggi, lembaga kelitbangan di daerah, pemerintah daerah, swasta dan masyarakat. Hasil analisis pemangku kepentingan di tiga kabupaten sampel dapat dilihat pada tabel di bawah ini.

Tabel 1. Analisis pemangku kepentingan di tiga kabupaten sampel

\begin{tabular}{llccccc}
\hline \multirow{2}{*}{ No. } & Kabupaten & \multicolumn{5}{c}{ Instrumen Penelitian } \\
\cline { 3 - 6 } & $\begin{array}{c}\text { Perguruan } \\
\text { Tinggi }\end{array}$ & $\begin{array}{c}\text { Lembaga } \\
\text { kelitbangan }\end{array}$ & Masyarakat & $\begin{array}{c}\text { Pemerintah } \\
\text { Daerah }\end{array}$ & Swasta \\
\hline 1 & Konawe & 3 & 1 & 1 & 1 & 0 \\
2 & Kolaka Timur & 0 & 1 & 0 & 0 & 1 \\
3 & Konawe Utara & 0 & 1 & 0 & 1 & 0 \\
\hline
\end{tabular}

Ket. Skor 0 : Tidak tersedia; Skor 1 : Rendah; Skor 2 : Cukup; Skor 3 : Sedang; Skor 4 : Tinggi

Sumber : Data primer diolah

Hasil kajian di tiga kabupaten sampel berdasarkan peran dari para aktor utama pengembangan sistem inovasi di daerah menunjukan di Kabupaten konawe lembaga kelitbangan seperti Balitbang konawe belum memberikan kontribusi penting dalam pengembangan sistem inovasi daerah. Lemahnya peran Balitbang tersebut dalam kontribusi pengembangan kelembagaan sistem inovasi di daerah adalah disebabkan karena belum terjalinnya komunikasi dan kerjasama yang intensif antara instansi teknis yang terkait dengan pembangunan pertanian di daerah, Bappeda sebagai instansi perencana dan Balai Pengkajian Teknologi Pertanian (BPTP) sebagai lembaga litbang kementrian Pertanian. Namun di sisi peran perguruan tinggi, peran lembaga pendidikan tersebut cukup memberi arti pada pembangunan pertanian di daerah dengan adanya kerjasama peningkatan kapasitas penelitian pertanian dengan pemerintah Korea Selatan.

kondisi di Kabupaten Konawe Utara menunjukan perbedaan yang tidak siginifikan dengan analisis pemangku kepentingan di Kabupaten Konawe. Nilai skor peran dari perguruan tinggi di Kabupaten Konawe Utara lebih rendah dari Kabupaten Konawe. Untuk budaya inovasi, masyarakat di Kabupaten Konawe utara memiliki skor terendah bila dibandingkan dengan Kabupaten Konawe, hal ini menunjukan tidak adanya budaya inovasi yang berkembang di Kabupaten Konawe Utara. Demikian juga dengan keterlibatan pihak swasta di Kabupaten Konawe Utara memiliki skor yang sama di Kabupaten Konawe. Hal ini menunjukan sektor swasta belum memiliki peran dalam kontribusi pengembangan sistem inovasi daerah. Padahal, di Kabupaten Konawe Utara memiliki beberapa perusahaan swasta yang bergerak di bidang perkebunan kelapa sawit dan pertambangan. Hasil yang tidak berbeda dengan Kabupaten Konawe Utara juga terlihat di Kabupaten Kolaka Timur Namun, nilai positif ditunjukan oleh skor yang lebih tinggi dibandingkan dengan di Kabupaten Konawe dan Kabupaten Konawe Utara pada peran masyarakat dalam menumbuhkembangkan budaya 
inovasi khususnya peran para petani kakao di Kolaka Timur dalam keterlibatan sistem inovasi daerah.

Hasil analisis pemangku kepentingan di tiga kabupaten sampel berdasarkan peran dari aktor utama dalam Sistem Inovasi Daerah menunjukan peran yang berbeda pada setiap kabupaten sampel. Namun secara umum menunjukan bahwa perguruan tinggi memiliki peran yang cukup penting dalam pengembangan SIDa walaupun skor menunjukan nilai yang berbeda. Di sisi lain peran masyarakat masih sangat rendah, hal ini dilihat dari budaya inovasi yang sangat rendah, sedangkan peran swasta masih belum diperlihatkan dalam fungsional kontribusi dalam pengembangan SIDa. Sisi yang menarik peran dari lembaga litbang (Balitbang dan BPTP) masih belum menunjukan eksistensinya dalam pengembangan Sistem Inovasi Daerah, hal ini disebabkan sinkronisasi dan koordinasi masih bersifat parsial (Julian, 2011). Hal ini juga sejalan dengan hasil penelitian (Dadit et al., 2012).

\section{Infrastruktur}

Kebijakan di bidang infrastruktur memilki peran strategis dalam penguatan kelembagaan Sistem Inovasi Daerah (SIDa). Dari hasil FGD disimpulkan empat pilar strategis pengembangan infrastruktur dalam upaya penguatan Sistem Inovasi Daerah (SIDa), yaitu : teknologi informasi dan komunikasi (Sri Nuryanti), regulasi, pelatihan dan pendanaan.

Hasil analisis infrastruktur pada Tabel 2 yang dilakukan di Kabupaten Konawe secara khusus dengan menggunakan skor penilaian 0- 2 menunjukan bahwa TIK memiliki nilai skor 2 yang menunjukan bahwa perkembangan teknologi informasi dan komunikasi di Balitbang Kabupaten Konawe sudah cukup baik namun masih perlu lebih dioptimalkan sehingga dapat lebih dirasakan manfaatnya. Untuk dukungan regulasi khususnya sistem inovasi daerah masih rendah (nilai skor 0,5 ), demikian pula dengan pengembangan SDM melalui pelatihan masih memiliki skor rendah (nilai skor 0,5), namun di sisi pendanaan pemerintah Kabupaten Konawe telah menunjukan komitmennya dalam pengembangan sistem inovasi. Hal ini dapat dilihat sejak berdirinya Balitbang Kabupaten Konawe telah konsisten untuk melakukan pendanaani bidang penelitian dan pengembangan di berbagai sektor.

Tabel 2. Analisis Infrastruktur di tiga kabupaten sampel

\begin{tabular}{cccccc}
\hline No. & Kabupaten & \multicolumn{3}{c}{ Instrumen Penelitian } \\
\cline { 3 - 6 } & $\begin{array}{c}\text { Teknologi } \\
\text { Informasi dan } \\
\text { Komunikasi }\end{array}$ & Regulasi & Pelatihan & Pendanaan \\
\hline 1 & Konawe & 2 & 0,5 & 0,5 & 2 \\
2 & Kolaka Timur & 2 & 0,5 & 0,5 & 0,5 \\
3 & Konawe Utara & 0,5 & 0,5 & 2 & 0,5 \\
\hline
\end{tabular}

Ket. Skor 0-1 : Rendah; Skor 1,5-2: Tinggi; Skor 4 : Tinggi

Sumber : Data primer diolah

Selanjutnya di Kabupaten Kolaka Timur menunjukan nilai skor yang lebih rendah dari Kabupaten Konawe dari sisi pendanaan (nilai skor 0,5 ), namun dari sisi regulasi, TIK dan pelatihan memiliki nilai skor yang sama dengan Kabupaten Konawe. Kondisi ini lebih disebabkan karena undur kelitbangan di Kabupaten Konawe Utara masih berada di instansi Bappeda sehingga masih tumpang tindihnya antara perencanaan dan kelitbangan yang mengakibatkan unsur kelitbangan di Bappeda belum mendapat prioritas dari sisi kebijakan. Sedangkan di Kabupaten Konawe Utara menunjukan skor yang cukup tinggi dari sisi pelatihan (skor 2), namun masih rendah dari sisi regulasi, TIk dan pendanaan dengan masing-masing skor 0,5. Hal ini menunjukan Kabupaten Konawe Utara Utara memiliki komitmen dalam pengembangan SDM dalam upaya penguatan Sistem Inovasi Daerah.

Secara ringkas dari hasil analisis di atas menunjukan masih lemahnya dukungan kebijakan infrastruktur yang meliputi peraturan tentang kelitbangan daerah, training dan pengembangan teknologi informasi di 3 kabupaten sampel. Kondisi ini menunjukan bahwa kesiapan lembaga kelitbangan di daerah untuk mendukung sistem inovasi daerah masih terhambat pada kurangnya kebutuhan sarana dan prasarana untuk melaksanakan kegiatan riset di daerah. Dukungan pendanaan secara umum masih menunjukan level yang terendah di 2 kabupaten sampel (Konawe Utara dan Kolaka Timur), walaupun unsur peningkatan kapasitas SDM melalui pelatihan menunjukan level yang baik namun lemahnya pendanaan dan dukungan regulasi membuat sistem inovasi di daerah berjalan lambat. 


\section{KESIMPULAN DAN SARAN}

Sistem inovasi merupakan basis bagi pembangunan pertanian regional khususnya di Sulawesi Tenggara. Oleh sebab itu, peran lembaga lembaga penelitian mutlak diperlukan sebagai ujung tombak kemajuan pembangunan pertanian ke depan. Hasil kajian yang dilakukan di tiga wilayah sampel menunjukan secara umum bahwa peran kelitbangan khususnya di lembaga penelitian di daerah seperti balitbang provinsi dan kabupaten belum secara optimal menjalankan peran dan fungsinya. Secara efektif. Hal ini disebabkan masih lemahnya sinkronisasi dan koordinasi dan masih bersifat parsial. Lebih lanjut, bahwa apa yang diharapkan dari lembaga kelitbangan dalam regulasi nya sebagai innovator masih banyak memiliki kelemahan dilihat dari sarana dan prasarana penelitian, pendanaan, dan budaya inovasi. Hasil penelitian ini diharapkan menjadi rekomendasi kebijakan bagi para pengambil kebijakan di pemerintah daerah agar supaya memberikan peran yang lebih besar bagi lembaga litbang di daerah melalui dukungan pendanaan, pelatihan fungsional peneliti, dan perbaikan sarana dan pra sarana.

\section{REFERENSI}

Boschma. (2015). Towards an evolutionary perspective on regional resilience. Regional Studies. Regional Studies, 49, 18.

Budi, T., Dian, P., Saut, S. (2013). Analisis Daya Saing Kluster Industri Unggulan Daerah: Studi Kasus Kluster Industri Alas Kaki: Pusat Penelitian Perkembangan IImu Pengetahuan dan Teknologi, Lembaga Ilmu Pengetahuan Indonesia

Dadit, H., Agung, P., \& Rolenta, E. (2012). Pemetaan Legislasi Kegiatan Perekayasaan, Inovasi, dan Difusi Teknologi pada Sistem Inovasi Nasional Jurnal Kebijakan Riset, Teknologi, dan Inovasi, 1, 19.

Dewi, Y.A. (2012). Inovasi spesifik lokasi untuk inkubator teknologi mendukung pengembangan ekonomi lokal Analisis Kebijakan Pertanian, 10(4), 13.

Indraprahasta S.G., Ramdhan, Alamsyah, P. (2014). Kesiapan daerah dalam meningkatkan daya saing daerah: Puspitek LIPI.

Julian, W. (2011). Koordinasi penelitian dan pengkajian teknologi pertanian di tingkat provinsi : Antisipasi Perbaikan Kinerja Komisi Teknologi Pertanian Analisis Kebijakan Pertanian., 9(3), 12.

Lakitan. (2011). Mewujudkan Sistem Inovasi Pertanian Daerah. Paper presented at the Menggali Potensi Daerah dalam rangka Mewujudkan Ketahanan Pangan Nasional, Jambi.

Lakitan. (2013). Kebijakan Sistem Inovasi dalam Membangun Pusat Unggulan Peternakan. Paper presented at the Makalah dipresentasikan dalam Seminar Nasional Forum Komunikasi Indusri Peternakan.

Narutomo. (2014). Program Penguatan Sistem Inovasi Daerah Sebagai Exit Strategy Program Nasional Pemberdayaan Masyarakat. . Jurnal Bina Praja, 6(2), 13.

Oki, O., \& Abu, A. (2014). Kajian struktur tata kelola sistem inovasi daerah (sida) provinsi banten Jurnal Lingkar Widyaswara, 1(1), 14.

Sri, N. (2011). Peran Kelompok Tani dalam Penerapan Teknologi Pertanian. Forum Penelitian Agro Ekonomi, 29(2), 13.

Susana, B. (2013). The Choice of Innovation Policy Instruments

Sverre J.H., Herstad, T.S., \& Bernd, E. (2015). Recruitment, knowledge integration and modes of innovation Research Policy, 44(1), 15.

Wiwandari H., Mada, S.Z., Satria, K. (2012). Kajian pengembangan sistem inovasi daerah (sida) kota semarang Riptek, 6(2), 6. 